\title{
Identifying the true origins of selectivity in chiral phosphoric acid catalyzed $N$-acyl- azetidine desymmetrizations
}

\author{
Pier Alexandre Champagne* \\ Department of Chemistry and Environmental Science, New Jersey Institute of Technology, \\ Newark, NJ, United States \\ pier.a.champagne@njit.edu
}

\begin{abstract}
The first catalytic intermolecular desymmetrization of azetidines was reported by Sun and coworkers in 2015 using a BINOL-derived phosphoric acid catalyst (J. Am. Chem. Soc. 2015, 137, 5895-5898). To uncover the mechanism of the reaction and the origins of the high enantioselectivity, Density Functional Theory (DFT) calculations were performed at the B97D3 / 6-311+G(2d,2p) / SMD(toluene) // B97D3 / 6-31G(d,p) / CPCM(toluene) level of theory. Comparison of four possible activation modes confirms that this reaction proceeds through the bifunctional activation of the azetidine nitrogen and the thione tautomer of the 2mercaptobenzothiazole nucleophile. Upon thorough conformational sampling of the enantiodetermining transition structures (TSs), a free energy difference of $2.0 \mathrm{kcal} \mathrm{mol}^{-1}$ is obtained, accurately reproducing the experimentally measured $88 \%$ e.e. at $80{ }^{\circ} \mathrm{C}$. This energy difference is due to both decreased distortion and increased non-covalent interactions in the pro$(S)$ TS. To uncover the true origins of selectivity, the TSs optimized with the full catalyst were compared to those optimized with a model catalyst through steric maps. It is found that the arrangements displayed by the substrates are controlled by strict primary orbital interaction requirements at the transition complex, and their ability to fit into the catalyst pocket drives the selectivity. A general model of selectivity for phosphoric acid-catalyzed azetidine desymmetrizations is proposed, which is based on the preference of the nucleophile and benzoyl group to occupy empty quadrants of the chiral catalyst pocket.
\end{abstract}

\section{Keywords}

Density Functional Theory, enantioselective organocatalysis, chiral phosphoric acid, azetidine desymmetrization, origins of enantioselectivity, distortion, non-covalent interactions

\section{Introduction}

The importance of chirality in all spheres of chemistry explains the ongoing extraordinary efforts toward developing stereoselective organic transformations. ${ }^{1,2}$ As new catalytic systems were discovered for this purpose, models of selectivity were also developed to satisfy the practitioners' urge to rationalize and predict experimental results, as well as inform future improvements. These qualitative "chemically-intuitive" models, which were at first derived purely from empirical data 
and then increasingly supported by computational chemistry, ${ }^{3}$ focused on describing the principal factors affecting the energy of transition structures (TS) leading to competing stereoisomers. Only recently, with the rise of electronic structure calculations such as Density Functional Theory (DFT), from which chemically-accurate geometries and energies can be obtained at a reasonable computational cost, ${ }^{4}$ can such TSs of asymmetric transformations be routinely computed as the first step in the development of selectivity models. ${ }^{5}$ Qualitative modeling can be computationally expensive due to the requirement of optimizing multiple diastereomeric TSs which can be complicated by the large conformational space of the catalsyst, but the resulting visualizations have been shown to provide intricate insights about the structures that can be distilled into chemically-intuitive explanations for the observed selectivity. ${ }^{6}$ A different approach to model stereoselective reactions without explicitly computing TSs is the statistical modeling, as popularized by Sigman. ${ }^{7-16}$ Such multivariate analyses allow for excellent quantitative predictions of enantioselectivity based on fitting experimental results to a set of physical organic chemistry descriptors, but their mechanistic interpretation is obfuscated behind complex equations often comprising cross-terms of parameters that have to be redefined for most regressions. Depending on the situation, chemically-intuitive or statistical modeling approaches can each be useful and should be considered as complementary instead of competing tools toward understanding and improving stereoselective transformations.

In the field of enantioselective organocatalysis, ${ }^{17}$ chiral phosphoric acids (CPAs) enjoy a strong reputation as versatile and powerful catalysts that are applicable to a variety of chemical reactions. ${ }^{18}$ As such, there has been significant effort deployed toward the computational study of asymmetric CPA-catalyzed reactions over the last decades. ${ }^{19}$ Reactions involving imines and other $s p^{2}$-hybridized carbon electrophiles are particularly well-studied experimentally and computationally (including multivariate analysis), ${ }^{10,20-32}$ yet few qualitative models have been proposed. Notably, Goodman and coworkers compiled an impressive breadth of quantitative computational data to develop their comprehensive qualitative model for imine additions, which focuses on the features making the TS leading to the major product favorable and explains why this arrangement is unfavorable for the minor enantiomer. The resulting eponymous Goodman model $^{22,33}$ is the gold standard in CPA catalysis, and similar models for other reaction types are highly desirable. One class of reactions that is understudied and that would benefit from improved understanding is the desymmetrization of aziridines, ${ }^{34-39}$ epoxides, ${ }^{40-42}$ azetidines, ${ }^{43}$ and oxetanes ${ }^{44-49}$ by ring-opening with nucleophiles. For such $s p^{3}$-hybridized carbon electrophiles, fewer experimental reports are known. Computational studies on these systems ${ }^{48,50-54}$ have relied on the optimization of stereodetermining TSs to identify if distortions or non-covalent interactions are major contributor to selectivity, but few general models have been proposed. ${ }^{51,54}$

We were intrigued that DFT studies of organocatalyzed reactions often provide clear insights about the selectivity-determining TSs, but rarely yield general models of selectivity. We hypothesized that the focus of recent computational studies and statistical analyses on comparing only the stereodetermining TSs prevents the identification of the true origins of selectivity that are 
necessary to develop chemically-intuitive models. To demonstrate this effect, we present a DFT study of the first catalytic intermolecular desymmetrization of meso-azetidines, which was reported in 2015 by Sun and coworkers. ${ }^{43}$ Although the desymmetrization of aziridines and azetidines is an important transformation giving access to chiral amines, ${ }^{55,56}$ Sun's report is still the only example in this reaction class. Their system is limited to benzoyl-protected azetidines as electrophiles and mercaptobenzothiazoles as nucleophiles, and there are no reports of extensions of this methodology. These limitations are not well understood, therefore studying this reaction presented a unique opportunity to uncover how its mechanism is linked to its selectivity, expand our understanding of such reactions and allow for new developments to occur.

\section{Methods}

Figure 1 reproduces the best optimization result from Sun et al., whereas meso $N$-acylazetidine 1, bearing a benzyloxy substituent at the 3-position, is reacted at $80^{\circ} \mathrm{C}$ with 2-mercaptobenzothiazole 2a under catalysis from BINOL-derived $(\boldsymbol{R})-\mathbf{3 a}$, forming $(\boldsymbol{S})-\mathbf{4 a}$ in $\mathbf{9 4 \%}$ yield and $\mathbf{9 5 \%}$ e.e. (system A). To reduce the computational cost associated with this study, we chose instead the example where the benzothiazole is unsubstituted $(\mathbf{2 b})$ and the catalyst bears a tris-(isopropyl)phenyl aryl substituent (3b), forming product $\mathbf{4 b}$ in $99 \%$ yield and $88 \%$ e.e. (system B). Sun's results indicate that the benzoyl group on the azetidine's nitrogen plays a key role in both reactivity and stereoinduction. Indeed, electron-poor benzamides were unreactive, while the 3,4,5-trimethoxy substitution pattern is crucial for high enantioselectivity. Electron-rich benzothiazoles were required for reactivity, but substitution was only tolerated at the 6-position for high selectivity. The reaction can be catalyzed by a range of BINOL-derived phosphoric acid catalysts, but only those with 2,6-iPr-4-R- $\mathrm{C}_{6} \mathrm{H}_{2}(\mathrm{R}=i \mathrm{Pr}$ or $\mathrm{Ad})$ groups provided high selectivity. Finally, a wide scope of substituent at the 3-position of the azetidine were tolerated without any impact on the high enantioselectivity, including alkyl or aryl ethers, alkanes, and arenes. Considering this experimental evidence, system $\mathbf{B}$ is a representative example of the transformation that did not require any approximations.
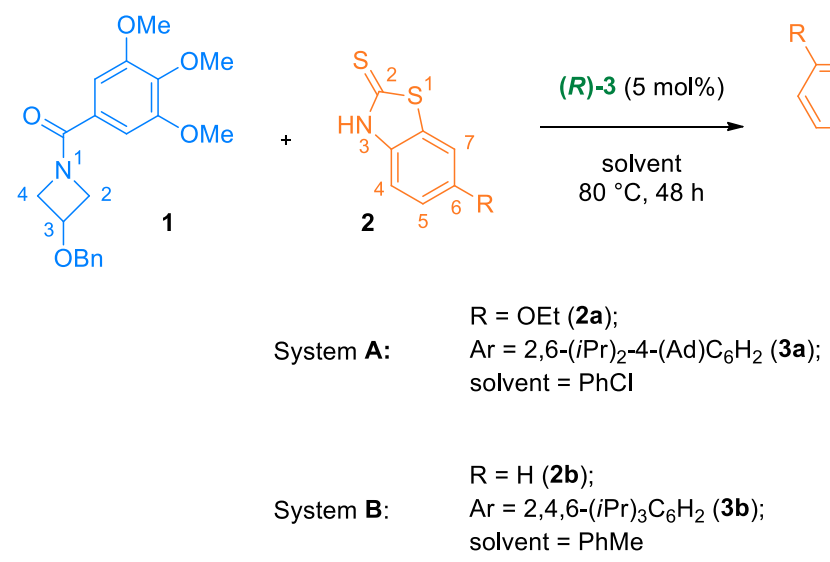
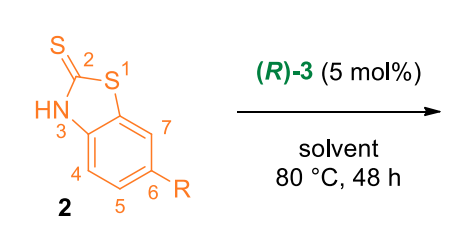

solvent $=\mathrm{PhMe}$
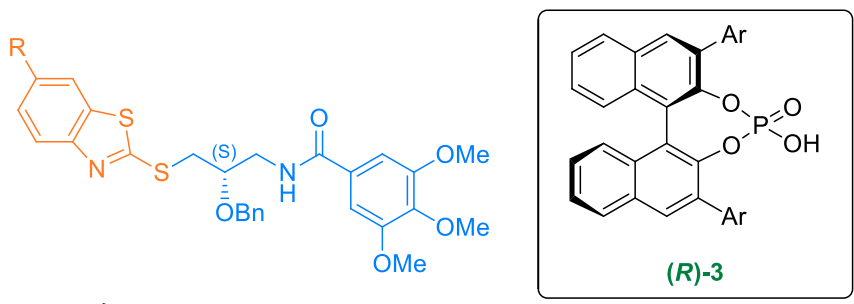

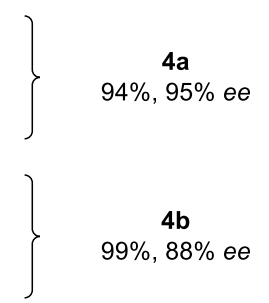


Figure 1: Selected examples of the enantioselective azetidine desymmetrizations reported by Sun. System A is the best reported system in the experimental study. System B is chosen as a computational target in this study. Ad = adamantyl

DFT geometry optimizations were performed with Gaussian 16 at the B97D3/6-31G(d,p) level of theory, ${ }^{57}$ with the CPCM implicit solvation ${ }^{58,59}$ model for toluene. This method has been shown to provide good results in previous DFT studies of CPA-catalyzed reactions ${ }^{52-54,60-62}$ and accounts for both dispersive interactions and solvation issues. Conformational sampling of each stationary point was performed using Grimme's CREST algorithm ${ }^{63}$ as implemented in the XTB code. ${ }^{64}$ Single-point energy (SPE) refinements were obtained with various methods, solvation models and basis sets, which all agreed on the relative free energies of the key stereodetermining TSs; the values from B97D3/6-311+G(2d,2p) with the SMD solvation model ${ }^{65}$ for toluene are presented in the main text as they are the most accurate. Visualizations of the structures were generated using CYLview. ${ }^{66}$ Full computational details can be found in the Supporting Information.

\section{Results}

Initially, we considered the tautomeric forms of 2-mercaptobenzothiazole $\mathbf{2 b}$ (more aptly named benzo $[d]$ thiazole-2(3H)-thione) (Figure 2A). Our results serve as a reminder that its thiol tautomer (2b-SH) is $8.3 \mathrm{kcal} \mathrm{mol}^{-1}$ less stable than its thione tautomer (2b-NH), thus its ground-state structure is not consistent with its usual drawing in the literature. That the thione tautomer is the major species in solution and the active nucleophile in such reactions has been known from other computational studies involving this nucleophile, ${ }^{52,53}$ and confirmed via ${ }^{13} \mathrm{C}$ NMR experiments by Pericàs and coworkers. ${ }^{67}$ 
<smiles>Cc1c(C)c(C)c(C)c(C)c1C</smiles><smiles>S=c1[nH]c2ccccc2s1</smiles>

$$
\begin{gathered}
2 \mathrm{~b}-\mathrm{NH} \\
\Delta \mathrm{G}=0.0
\end{gathered}
$$<smiles>CCC1CC2C(C)=C(C)C(C)=C(C)C2O1</smiles>

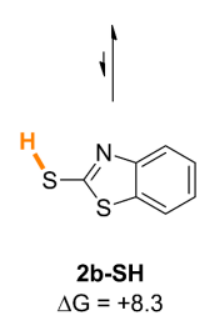

C. Reaction Diagram

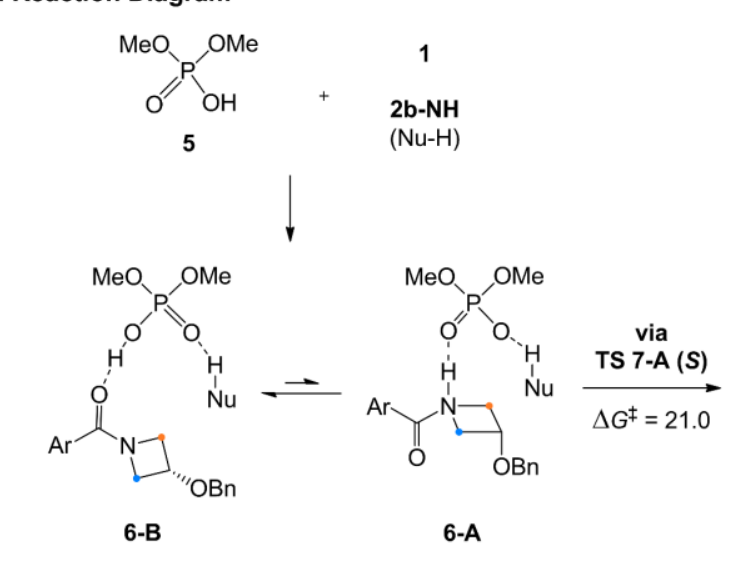

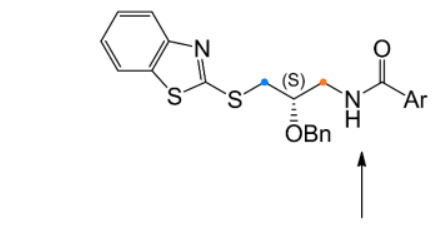

$(S)-4 b$

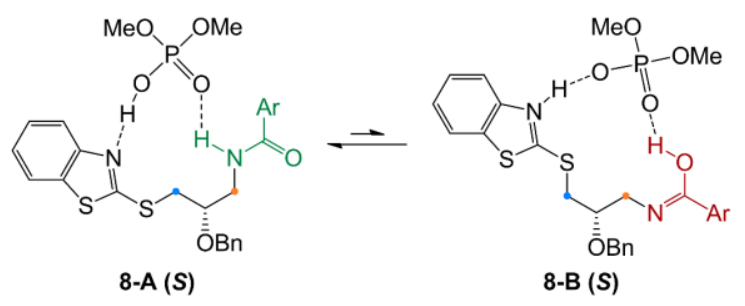

Figure 2: A. Free energy difference (in $\mathrm{kcal} \mathrm{mol}^{-1}$ ) between the thiol and thione tautomers of $\mathbf{2 b}$. B. Free energy profile for the reaction of $\mathbf{1}$ with $\mathbf{2 b}$ catalyzed by model catalyst $\mathbf{5}$, using modes A and B. Non-critical hydrogen atoms are hidden for improved clarity on the visualized structures. C. Reaction diagram.

Then, to study the mechanism of the transformation and the preferred conformations of the transition structures (TS) leading to the $(R)$ - and $(S)$-products, we used dimethoxyphosphoric acid (5) as a model truncated catalyst, keeping a fixed conformation in line with the axial chirality of $(\boldsymbol{R})-3$. This approach has been used successfully in previous work, ${ }^{51,54,62}$ and the lowest-energy TSs located with the small catalyst often mimicked those obtained with the large BINOL- (or SPINOL-) derived catalyst, indicating that low-energy TS arrangements are independent of the catalyst's cavity shape (see below). In agreement with the known catalytic behavior of CPAs which predominantly activate both nucleophile and electrophile simultaneously via bifunctional activation, ${ }^{18}$ four possible activation modes were explored computationally. These possibilities 
arise as the acyl-azetidine substrate $\mathbf{1}$ can be activated by protonation of the nitrogen or oxygen atom of its amide moiety, while nucleophile $\mathbf{2} \mathbf{b}$ can be activated from its two tautomeric (thiol or thione) forms. Of those possibilities, mode $\mathrm{A}$, where the azetidine ring nitrogen and the thione tautomer are activated, has the lowest activation free energy, followed by mode B where the azetidine is instead activated via the carbonyl.

The PES and rate-determining TSs for these two pathways en route to the major $(S)$-product are shown in Figure 2B. In mode A, the reactant complex (RC) exhibits a complete transfer of the phosphoric acid proton to the azetidine nitrogen (6-A, Figure 2C). The most stable RC located for this system uses mode $\mathrm{B}\left(\mathbf{6}-\mathbf{B},-5.9 \mathrm{kcal} \mathrm{mol}^{-1}\right)$, in line with the increased basicity of amide carbonyls versus nitrogens. However, the TS for nucleophilic attack has a lower free energy in mode A (TS 7-A, $\Delta \mathrm{G}^{\ddagger}=21.0 \mathrm{kcal} \mathrm{mol}^{-1}$ from 6-B), while mode B entails an $8.2 \mathrm{kcal} \mathrm{mol}^{-1}$ penalty (TS 7-B, $\Delta \mathrm{G}^{+}=29.2 \mathrm{kcal} \mathrm{mol}^{-1}$ ). The high energy of the TS using mode $\mathrm{B}$ is likely related to the unfavorable imidic acid tautomer of the amide which is initially formed using this pathway (8-B $\left.(S), 1.0 \mathrm{kcal} \mathrm{mol}^{-1}\right)$. The reaction is under kinetic control (irreversible), due to the stability of the product-complex (PC) 8-A $(\boldsymbol{S})\left(-15.9 \mathrm{kcal} \mathrm{mol}^{-1}\right)$. TSs using the thiol tautomer of the benzothiazole (2b-SH) were significantly higher in energy; thiol and amide nitrogen activation (mode C) is 14.5 $\mathrm{kcal} \mathrm{mol}^{-1}$ higher than mode A, while the combination of thiol and oxygen activation (mode D) is $19.9 \mathrm{kcal} \mathrm{mol}^{-1}$ higher (see Figure S2 for the structures of modes B-D). Overall, these results agree with the preliminary work from $\mathrm{Sun}^{43}$ and confirm that mode A is the only reaction pathway that is operative in this system.

Bifunctional activation, especially with displaced nucleophiles like 2b-NH (i.e. where deprotonation occurs from an atom conjugated with the nucleophilic sulfur), have very strict orbital requirements, or primary orbital interactions. For TS 7-A, nucleophilic attack must occur from the $\mathrm{p}_{\mathrm{x}}$ lone pair of sulfur (orthogonal to the aromatic $\pi$ system) into the azetidine's $\sigma^{*}{ }_{\mathrm{C}-\mathrm{N}}$, following the $\sim 180^{\circ}$ angle prescribed for $\mathrm{S}_{\mathrm{N}} 2$ reactions. Simultaneously, the azetidinium's $s p^{3} \mathrm{~N}$ $\mathrm{H}$ and the benzothiazole's $s p^{2} \mathrm{~N}-\mathrm{H}$ bonds must form hydrogen bonds with two of the phosphate's oxygen $s p^{2}$ lone pairs (at a roughly $120^{\circ} \mathrm{P}-\mathrm{O}-\mathrm{H}$ angle). These requirements, along with the extent of bond breaking and bond forming due to the position of the TS along the reaction coordinate, make for a highly rigid transition complex (TC, the substrates in their TS geometry). This TC can, however, adopt different arrangements relative to the phosphoric acid's core structure, in addition to conformations arising from rotation around single bonds.

The arrangements located for TS 7-A $(\boldsymbol{R}$ and $S$ ) are depicted in Figure 3. For the pro- $(S)$ TS (Figure 3A), the best arrangement involves protonation of the azetidine trans from the benzyloxy substituent (Figure 3D), with the nucleophile's benzothiazole ring perpendicular from the phosphoric acid's structure. For the pro- $(R)$ TS (Figure 3B), the best arrangement is similar to the pro-(S) TS, except protonation occurs cis to the substituent which now projects toward the catalyst structure, allowing the nucleophile to attack the opposite azetidine carbon. Eight other 
arrangements of the pro- $(R)$ TC were located (Figure 3C), all of which displaying trans protonation yet at least $1.8 \mathrm{kcal} \mathrm{mol}^{-1}$ less favorable than TS 7-A $(\boldsymbol{R})$. Two higher-energy arrangements were also located for TS 7-A $(S)$. For each arrangement, many conformers were located, some with free energy differences as small as $0.2 \mathrm{kcal} \mathrm{mol}^{-1}$ (for other arrangements of TS 7-A (S) and examples of conformers, see Figures S3-S5). Overall, despite the varied tridimensional shapes of the arrangements, the primary orbital interactions kept the forming and breaking bond lengths in a narrow range $(\mathrm{S} \cdots \mathrm{C}$ bond between 2.53 and $2.61 \AA$ and $\mathrm{C} \cdots \mathrm{N}$ bond between 1.96 and $2.02 \AA$ ). This indicates that even without the large groups on the BINOL-derived catalyst $(\boldsymbol{R})-\mathbf{3 b}$, the main difference between the pro- $(R)$ and pro- $(S)$ TSs is the orientation of the azetidine during the protonation.

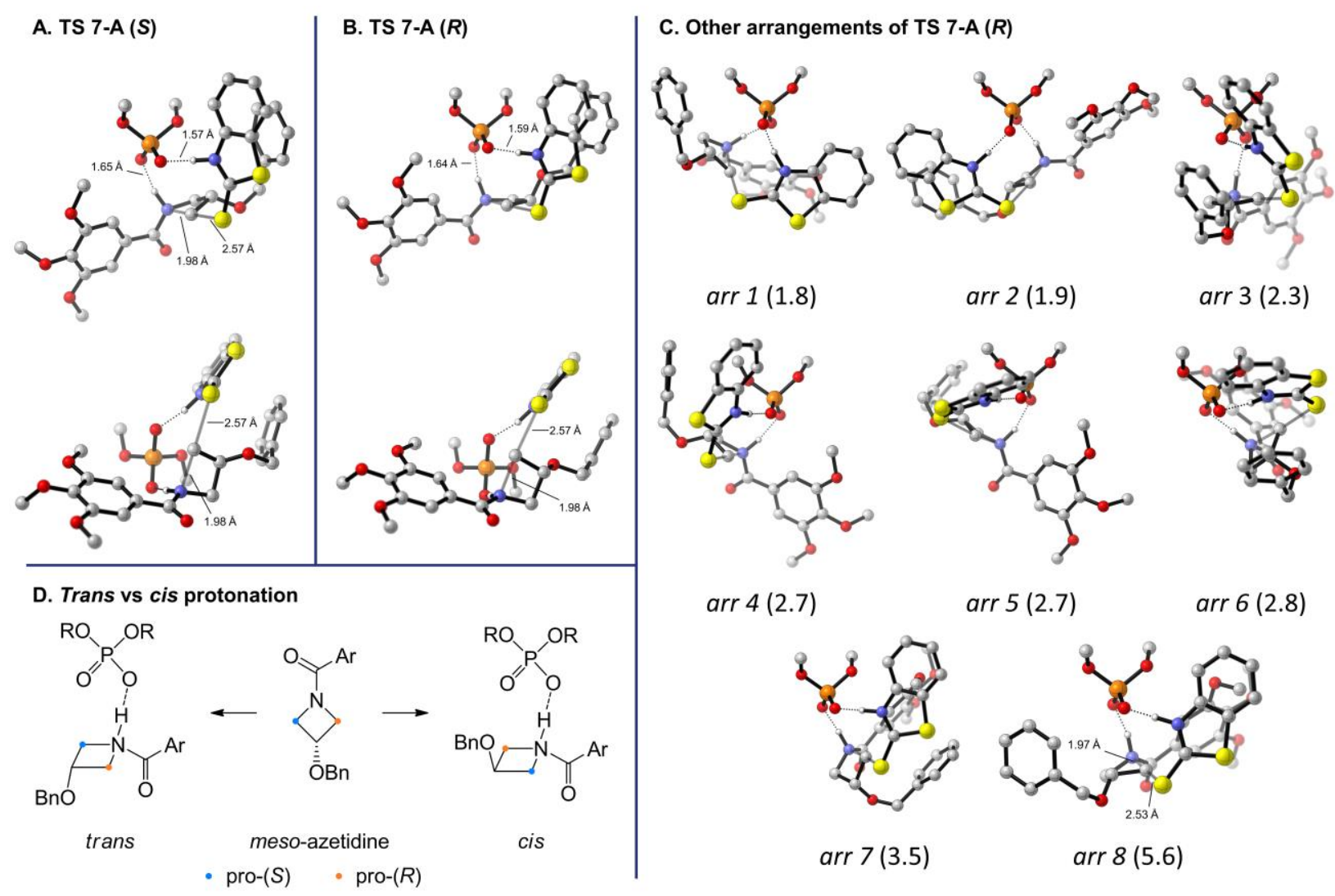

Figure 3: A. Goodman (top) and quadrant (bottom) projections of the lowest-energy TS 7-A (S). B. Goodman (top) and quadrant (bottom) projections of the lowest-energy TS 7-A (R). C. Other located arrangements of the pro- $(R)$ transition complex relative to the phosphoric acid catalyst, shown in the Goodman projection. Free energies relative to TS 7-A $(\boldsymbol{R})$ (in $\mathrm{kcal} \mathrm{mol}^{-1}$ ) listed in parenthesis. D. Trans vs cis protonation of meso-azetidine 1. For all computed structures, noncritical hydrogen atoms are hidden for improved clarity. 
With the mechanism confirmed as operating via amide $N$-protonation (mode A) and under CurtinHammett control, the origins of selectivity were investigated by computing the stereodetermining TSs for the reaction using the full catalyst $(\boldsymbol{R})-3 \mathbf{b}$. For the TSs leading to the experimentally preferred $(S)$-product, 19 unique conformers were located within a free energy span of $4.6 \mathrm{kcal}$ $\mathrm{mol}^{-1}$. Of those, only 5 structures were within $1.2 \mathrm{kcal} \mathrm{mol}^{-1}$ of the lowest in energy (all within 0.6 $\mathrm{kcal} \mathrm{mol}^{-1}$ ) and showed only minor conformational changes to the methoxy groups of the substrate or the isopropyl groups at the 4- and 4'-positions of the catalyst walls (see Figure S1). For the pro$(R)$ TSs, 45 unique conformers were located in a range of $5.3 \mathrm{kcal} \mathrm{mol}^{-1}$ and there were 13 structures within $1.2 \mathrm{kcal} \mathrm{mol}^{-1}$ with various conformations of the flexible benzyloxy substituent at the 3-position of the azetidine. Of note, the substrates, transition structures and products are strongly stabilized within the pocket of $(\boldsymbol{R})-\mathbf{3 b}$, as displayed in the PES for the full catalyst (Figure S6). In particular, the computations predict that the products of the reaction (especially of the minor $(R)$-enantiomer) bind more strongly than the substrates to the catalyst (the $\Delta G_{\text {binding }}$ of the $(R)$ product is $-15.3 \mathrm{kcal} \mathrm{mol}^{-1}$, while it is $-10.3 \mathrm{kcal} \mathrm{mol}^{-1}$ for the best reactant complex). Therefore, the product complexes are the turnover-determining intermediates ${ }^{68}$ in this system and significant product inhibition is expected. This is in line with the long reaction times $(48 \mathrm{~h})$ at $80{ }^{\circ} \mathrm{C}$ that were required for complete conversion. ${ }^{43}$ Mode $\mathrm{B}$ is around $19 \mathrm{kcal} \mathrm{mol}^{-1}$ higher in free energy than mode A within $(\boldsymbol{R})-\mathbf{3 b}$, further confirming that only mode A is operative within the BINOLderived catalyst. This can be explained from the fact protonation on the azetidine nitrogen ensures the benzoyl protecting group faces away from the catalyst backbone, while protonation of the carbonyl forces the benzoyl group to interfere with the catalyst (Figure S6) in addition to generating a worse imidic acid leaving group.

The lowest-energy structures leading to the $(S)$ - (left column) and $(R)$ - (right column) enantiomers of the product are shown in Figure 4 as their Goodman ${ }^{33}$ (top row) and Terada-Himo ${ }^{69,} 70$ "quadrant" (bottom row) projections. As protonation of the azetidine occurs at a roughly $109^{\circ}$ angle from the plane of its ring, it is best positioned directly under the phosphoric acid moiety (Figure 4A-B). The nucleophile adopts an orientation parallel to the $\mathrm{C}_{2}$-symmetric axis of the catalyst in one of its empty quadrants, while the benzamide leaving group occupies the opposite empty quadrant (Figure 4C-D). Interestingly, this arrangement of the substrates under the phosphoric acid catalyst is almost identical to what was observed with the model catalyst $\mathbf{5}$ (compare Figure 4 to Figure 3A-B) and is reminiscent of oxetane, oxirane and aziridine openings. ${ }^{48,50-54}$ As was identified with the model catalyst, protonation happens trans to the azetidine substituent in TS $9(S)$ and cis in TS $9(\boldsymbol{R})$ (Figure 4C-D). The cis approach in TS $9(\boldsymbol{R})$ is accompanied by significant puckering of the $\mathrm{C} 3$ position in the ring (dihedral angle of $14^{\circ}$ in $\mathbf{T S}$ $9(\boldsymbol{R})$, only $5^{\circ}$ in TS $\left.9(S)\right)$. In addition, the benzyloxy side chain adopts a partially eclipsed conformation vs the C3 hydrogen in TS $9(\boldsymbol{R})$ (dihedral angle of $40^{\circ}$ ), while a perfect staggered conformation is obtained in TS $9(S)$ (dihedral angle of $58^{\circ}$ ). Both of these conformational changes likely occur to prevent clashes between the substituent and the catalyst wall, which are otherwise in close proximity. Overall, the calculations agree that the $(S)$-product is favored in this reaction, as TS $9(S)$ is lower in free energy than TS $9(R)$ by $2.0 \mathrm{kcal} \mathrm{mol}^{-1}$. This $\Delta \Delta G^{\ddagger}$ value accounts for $89 \%$ e.e. at $80{ }^{\circ} \mathrm{C}$, in excellent agreement with the $88 \%$ e.e. measured experimentally. 


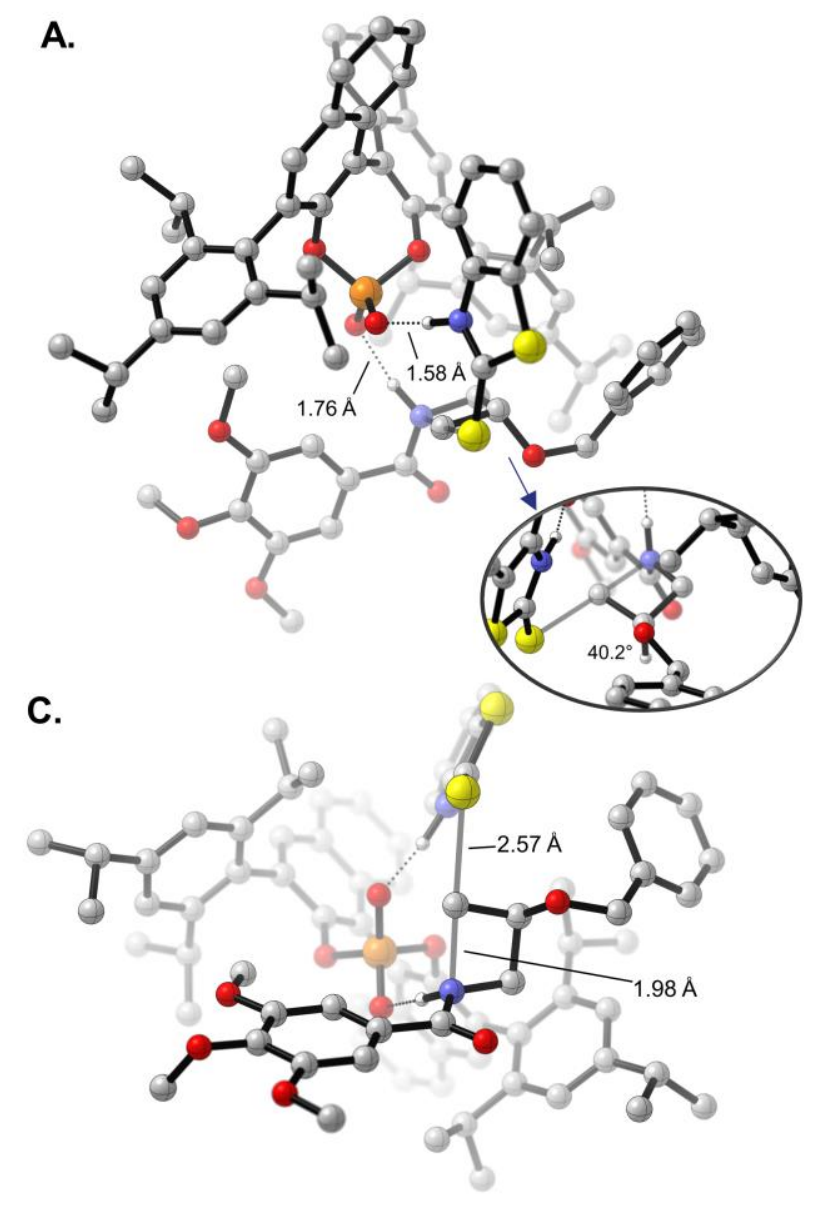

TS 9 (S)

$\Delta \Delta G^{\ddagger}=0.0$
B.
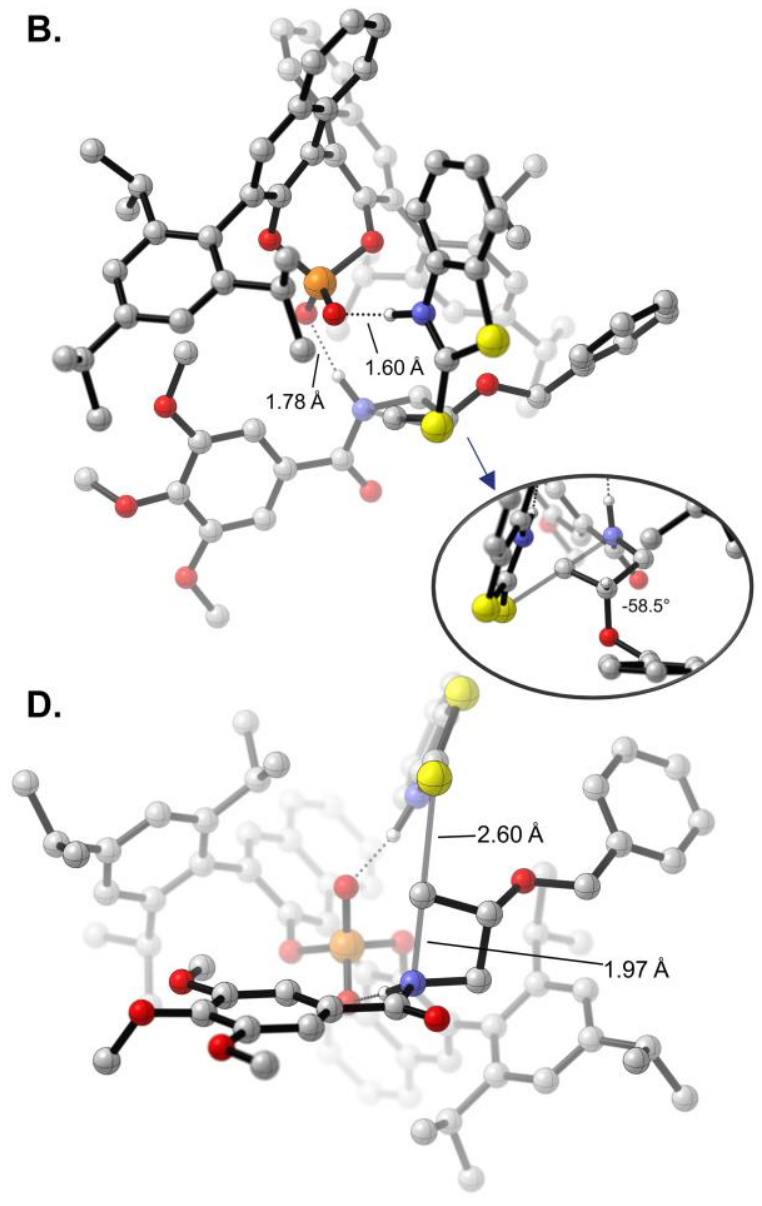

TS $9(R)$

$\Delta \Delta G^{\ddagger}=\mathbf{2 . 0}$

Figure 4: Lowest-energy TSs leading to the major $(S)$ and minor $(R)$ products for the reaction of $\mathbf{1}$ and $\mathbf{2 b}$ catalyzed by $(\boldsymbol{R})-\mathbf{3 b}$. Top row: Goodman projection. Bottom row: quadrant projection. Free energies are in $\mathrm{kcal} \mathrm{mol}^{-1}$ and were obtained at the B97D3/6-311+G(2d,2p)/SMD(toluene) // B97D3/6-31G $(\mathrm{d}, \mathrm{p}) / \mathrm{CPCM}$ (toluene) level of theory. Non-critical hydrogen atoms are hidden in the visualized structures to improve clarity.

Distortion/interaction (D/I) analysis ${ }^{71}$ of the TSs was performed by treating the structures as binary complexes between an anionic phosphate catalyst, and a cationic transition complex (azetidine + nucleophile, Figure S8). Due to the charged nature of the fragments, D/I analysis performed under various levels of theory gave different values for each component, although all methods agreed that TS $9(\boldsymbol{S})$ exhibits both lower distortion and stronger interactions than TS $9(\boldsymbol{R})$. The B97D3/6$311+\mathrm{G}(2 \mathrm{~d}, 2 \mathrm{p})$ level without the solvation model was identified as the best method (Table S2) for this analysis. At that level of theory, the energy difference $\left(\Delta \Delta \mathrm{E}^{\ddagger}=\Delta \mathrm{E}(R)-\Delta \mathrm{E}(S)\right)$ of $3.4 \mathrm{kcal}$ $\mathrm{mol}^{-1}$ is split into the distortion energy of the transition complex (azetidinium + benzothiazole, $\Delta \Delta \mathrm{E}^{\ddagger}$ dist-complex $\left.=1.2 \mathrm{kcal} \mathrm{mol}^{-1}\right)$, the interaction energy between the anionic catalyst and that 
complex $\left(\Delta \Delta \mathrm{E}^{\ddagger}\right.$ int $\left.=1.7 \mathrm{kcal} \mathrm{mol}^{-1}\right)$, and the distortion of the catalyst $\left(\Delta \Delta \mathrm{E}^{\ddagger}\right.$ dist-catalyst $^{+}=0.5 \mathrm{kcal} \mathrm{mol}^{-}$ $\left.{ }^{1}\right)$. Therefore, the free energy difference between the two stereodetermining structures is due to a combination of distortion and interactions. The large difference in distortion energy of the transition complex can be tracked down to the above-mentioned conformational changes in the azetidinium ring, since the distortion energy difference for the benzothiazole fragment is 0.0 . The large difference in interaction energy is due to unequal non-covalent interactions (NCI) as visualized through NCI plots ${ }^{72}$ using the Multiwfn software. ${ }^{73}$ In both structures, favorable van der Waals (dispersive) interaction zones are found between many regions of the catalyst structure and the benzothiazole, methoxy substituents of the benzamide, azetidine ring methylenes, or benzyloxy group of the substrates (Figure S9). For TS $9(S)$, larger interaction zones can be seen between the aromatic ring of the benzyloxy group and isopropyl substituent of the catalyst. However, the distortion and non-covalent interactions listed above are specific to substrate $\mathbf{1}$ and thus cannot be generalized to all available substrates in this reaction. Although they explain how the stereodetermining TSs studied here have different free energies, they are not the true origins of selectivity.

\section{Identifying the true origins of selectivity}

The above analysis would indicate that the size of the azetidine substituent is driving the selectivity since in TS $9(\boldsymbol{R})$ that substituent induces distortions raising the free energy of that structure. However, the scope of the Sun transformation shows that the catalytic system tolerates a wide variety of substituents on the substrate with minimal changes to the enantioselectivity. Similarly, as the trimethoxybenzoyl protecting group on the azetidine rests in the same position in TS $9(S)$ and TS $9(\boldsymbol{R})$ (Figure 4), an obvious conclusion would be that it has no effect on the selectivity. Again, that is incorrect, as less crowded protecting groups on the azetidine lead to lower experimental enantioselectivity. The major issue is that D/I analysis, NCI plots and other conventional approaches focus on the symptoms of the selectivity, namely differences in geometry and energy between the two lowest-energy enantiodetermining TSs. Thus, these approaches do not explain why the two TSs are different. Considering TS $9(S)$ exhibits the best arrangement with the protonation occurring trans from the substituent, why is the best TS $9(\boldsymbol{R})\left(2.0 \mathrm{kcal} \mathrm{mol}^{-1}\right.$ less favorable than the pro-(S) TS) occurring through an arrangement with the 3-substituent cis to the catalyst instead of any of the available trans arrangements (Figure 3C)? To identify the true origins of selectivity, we believe that we must uncover why TS $9(S)$ and TS $9(\boldsymbol{R})$ adopt geometries that are energetically different, and not simply compare their optimized structures.

To illustrate this idea that comparing the optimized TSs leading to the major and minor products only displays the consequences of the true origin of selectivity, we turned to visualizations based on the steric maps pioneered by Cavallo. ${ }^{74-79}$ Such visualizations have been applied successfully for transition metal-catalyzed reactions, but not to organocatalyzed transformations. ${ }^{28,80-84}$ Using the SambVca 2.1 tool, ${ }^{85}$ the arrangements displayed with the full catalyst $(\boldsymbol{R})-\mathbf{3 b}$ were compared to those using the model dimethoxyphosphoric acid catalyst $\mathbf{5}$. As mentioned above, for the pro- 
(S) TSs, the lowest-energy structure using the model catalyst has the same arrangement than with the full catalyst, barring minor conformational changes around the benzyloxy group. When the best model TS (TS 7-A $(S)$, Figure 5B) is superimposed with the catalyst (Figure 5A, see SI for details), both the benzothiazole and the trimethoxybenzoyl groups align with empty quadrants of the catalyst pocket (Figure 5C). Comparing this superimposition to the optimized TS 9 (S) (Figure 5D) shows that only a minor reorganization of the flexible substituent is required so the best structure for the $(S)$-leading TS fits easily in catalyst $(\boldsymbol{R})-\mathbf{3 b}$. This is a clear indication that the arrangements of substrates and catalysts in such TSs are governed by primary orbital interactions that dictate key bond lengths and angles. Fitting of this rigid transition complex in the catalyst pocket needs to happen before conformational changes occur to lower the distortion energy, or favorable non-covalent interactions appear between the substrates and catalyst.

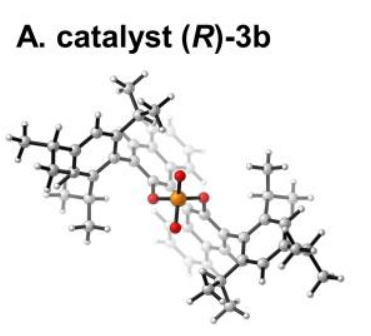

B. TS 7-A (S)

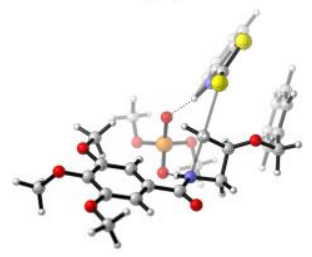

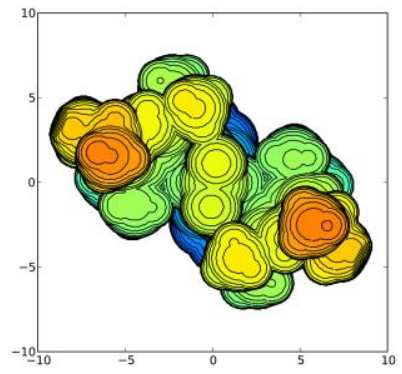

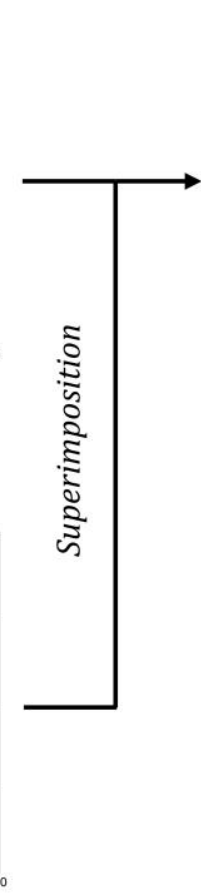

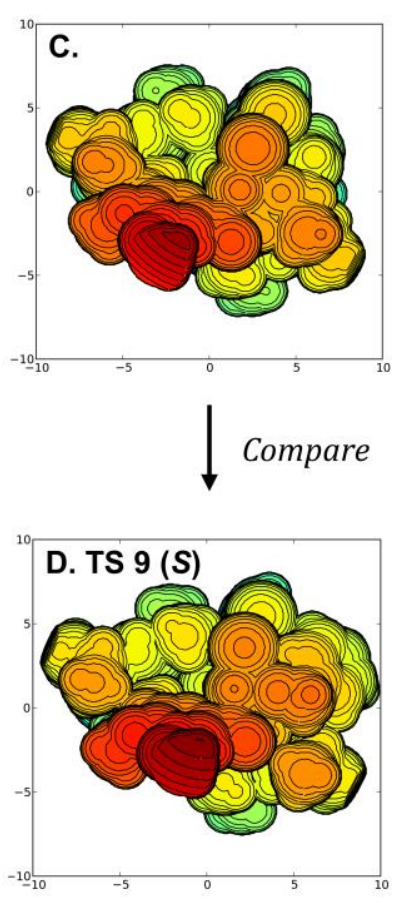

Scale

( $z$ axis)

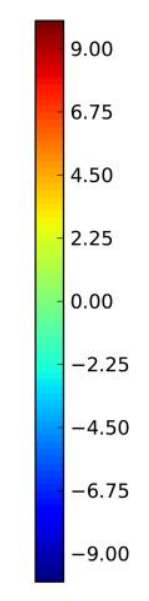

Figure 5: Steric map visualizations for the superimposition of TS 7-A $(S)$ with catalyst $(\boldsymbol{R})-3 \mathbf{b}$, compared to TS $9(S)$ Steric maps show the structures with their quadrant projection aligned with the $z$ axis, visualized as a sphere of $10 \AA$ radius with the phosphorus atom as the origin. Distances are in $\AA$, and the distance along the $z$ axis is color-coded from blue $(-10 \AA)$ to red $(10 \AA)$.

To generate the $(R)$-enantiomer of the product, two main approaches are possible. First, the arrangement with $c i$ s protonation can be used, projecting the substituent toward the catalyst as was favored with the model catalyst (TS 7-A $(\boldsymbol{R})$, Figure 6A). Superimposition of this model structure into the full catalyst pocket shows a mostly favorable fit, placing all large and rigid groups in empty quadrants of the catalyst structure. TS $9(\boldsymbol{R})$ (Figure 6B) is very similar to that superimposition, except for conformational changes that alleviate unfavorable contacts between 
the substituent and crowded catalyst backbone. We then wondered why the trans arrangements did not compete, though they would de facto position the substituent away from the catalyst, so we optimized the located trans arrangements shown in Figure $\mathbf{3}$ within the full catalyst (R)-3b. The resulting structures are heavily distorted and energetically unfavorable. (see Figure $\mathbf{S 7}$ for all structures). The best structure is derived from arrangement 3 (Figure 6C), rotating the reaction axis (RA, green arrow) away from the phosphoric acid's $\mathrm{C}_{2}$-symmetric axis (PAA). When this arrangement is superimposed with the catalyst, the nucleophile occupies an empty quadrant (blue arrow \#1), but the benzoyl group clashes with the catalyst wall (orange arrow \#2). Full optimization of this structure induces large reorganizations, especially in the benzoyl group, and the final structure is $5.1 \mathrm{kcal} \mathrm{mol}^{-1}$ higher in free energy than TS $9(\boldsymbol{R})$. Another approach is derived from arrangement 8, bringing the RA closer to the PAA (Figure 6D). This positions the nucleophile in an empty quadrant (blue arrow \#1), but results in clashes between both the benzyloxy substituent (orange arrow \#2) and the benzoyl group (orange arrow \#3) with the two walls of the catalyst. The resulting fully-optimized structure is $7.8 \mathrm{kcal} \mathrm{mol}^{-1}$ less stable than TS 9 $(\boldsymbol{R})$, as it requires significant distortion of the catalyst structure. Therefore, none of the trans arrangements, which should in principle be preferable, actually fit the catalyst pocket due to the large benzoyl substituent.

A. TS 7-A (R)

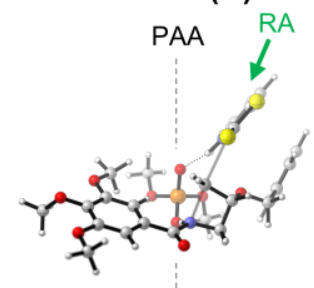

C. TS 7-A (R) (arr 3)

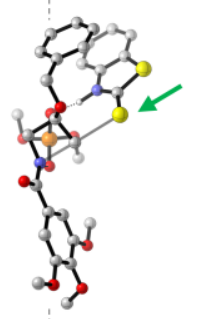

D. TS 7-A (R) (arr 8)

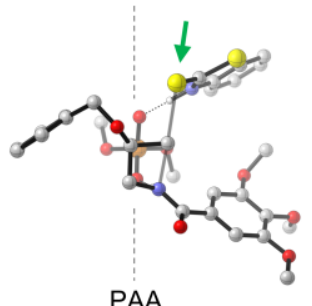

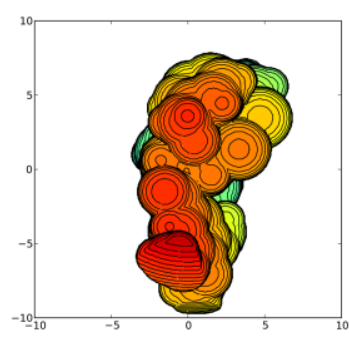
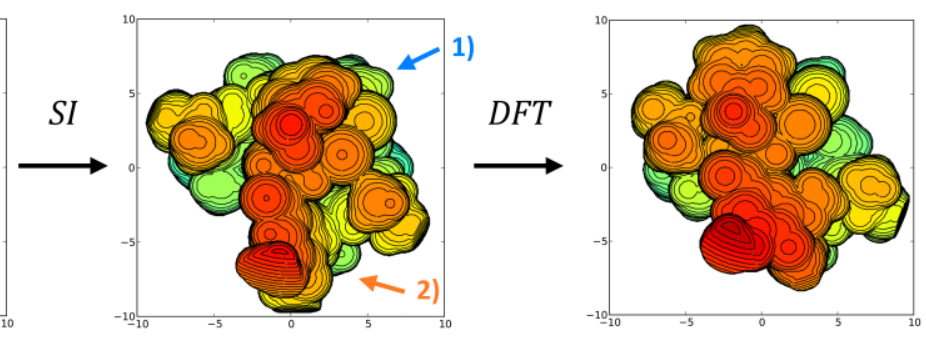

B. TS $9(R)$
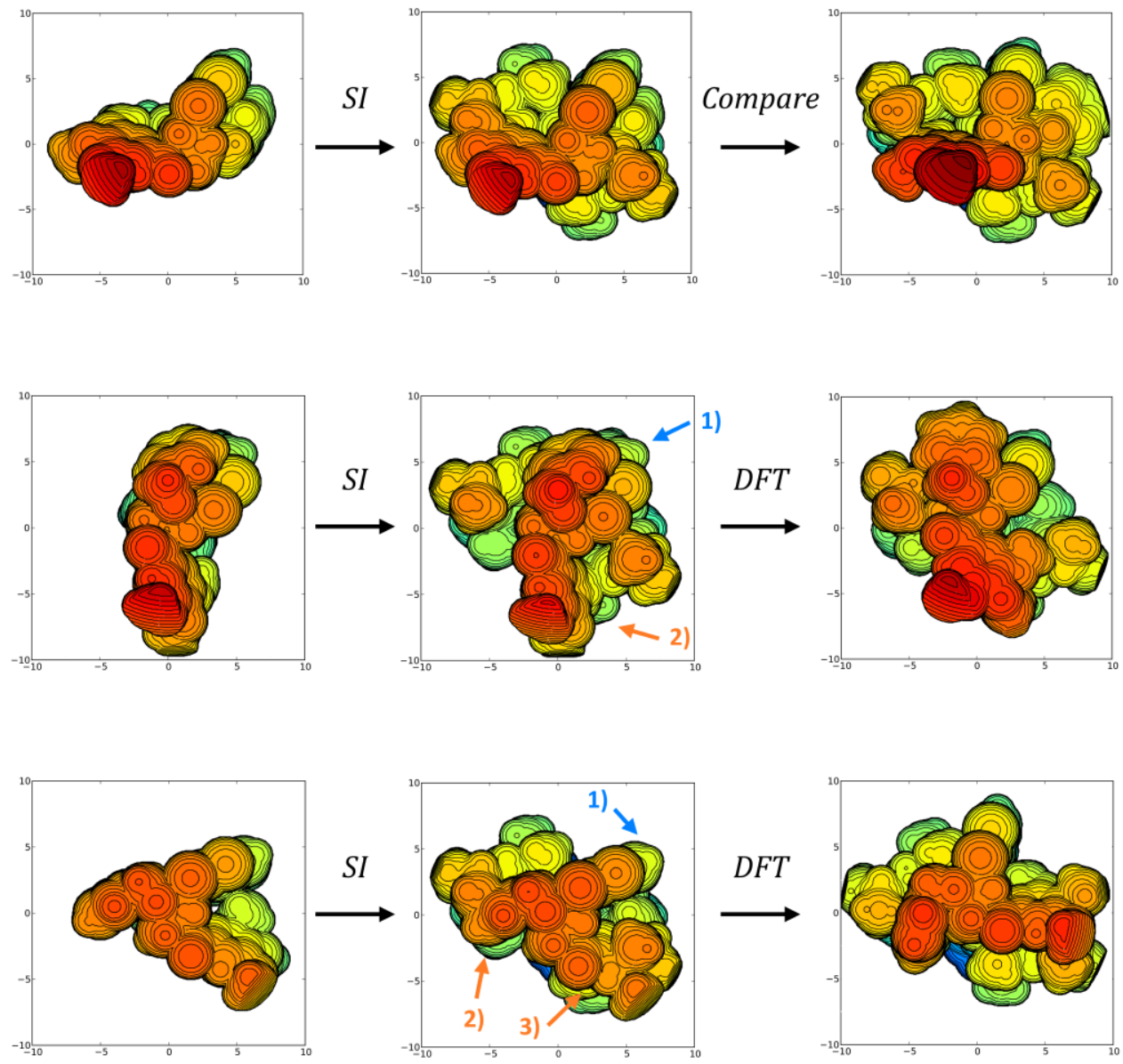
Figure 6: From left to right: quadrant projection and steric map of TS 7-A $(\boldsymbol{R})$ arrangements, superimposition of the structures on catalyst $(\boldsymbol{R})-\mathbf{3 b}$, and DFT-optimized TS in the full catalyst. PAA: Phosphoric acid $\mathrm{C}_{2}$-symmetric axis; RA: Reaction axis (green arrows); SI: superimposition on the catalyst structure; DFT: DFT optimization of the structure. Steric maps show the structure with the same orientation, scale and color code as Figure 5, above.

\section{Model of selectivity}

To fit into the catalyst pocket, the important features from the transformation's strict primary orbital requirements are the following: A) Positioning of the TS as to align the $S_{N} 2$ axis with the empty quadrants. The alignment of the reaction axis with the empty quadrant is general to intermolecular openings of strained $\mathrm{sp}^{3}$-hybridized electrophiles, regardless of the nature of the nucleophile. ${ }^{39,50-53}$ B) Positioning the benzothiazole nucleophile perpendicular to the reaction axis, where it can engage in favorable $\mathrm{C}-\mathrm{H} \cdots \pi$ interactions ${ }^{86}$ with the catalyst's binaphthyl backbone (Figure 7). Interestingly, this would explain why substituents at the 4- or 5-positions of the benzothiazole were not well tolerated in this reaction. ${ }^{43} \mathrm{C}$ ) Positioning of the azetidine's benzoyl group in an empty quadrant. D) Positioning of the 3-substituent of the meso-azetidine trans from the catalyst structure. DFT studies of similar systems have consistently shown that ring substituents preferentially point away from the catalyst. ${ }^{39,50-53}$

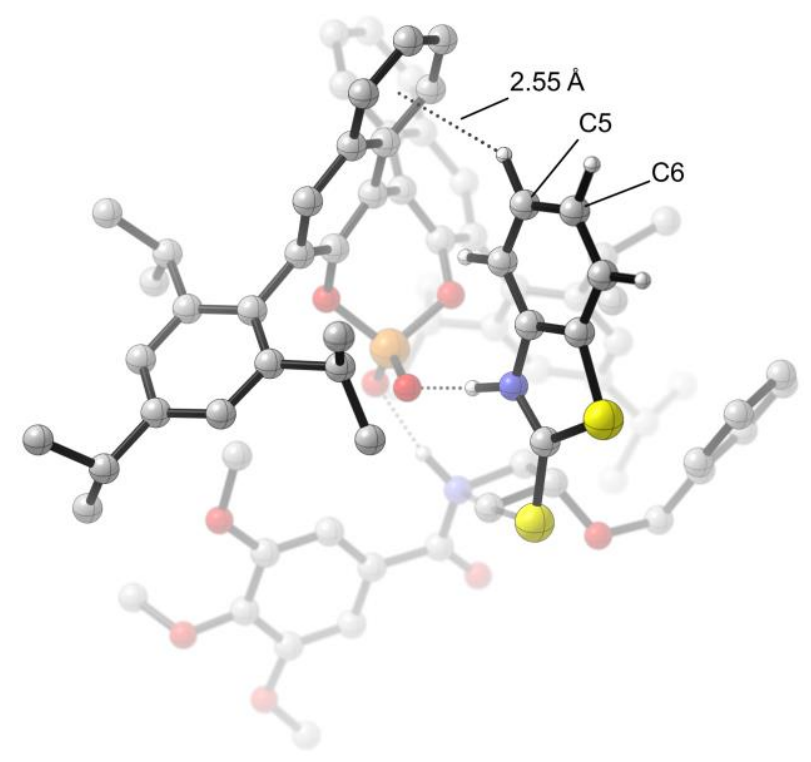

Figure 7: Close up of TS $9(S)$, showcasing how the nucleophile's plane is aligned with the catalyst's $\mathrm{C}_{2}$-symmetric plane. The $\mathrm{C}-\mathrm{H} \cdots \pi$ interaction is highlighted. Non-critical hydrogen atoms are hidden for improved clarity.

A general model of selectivity for this reaction is proposed in Figure 8. With the $(R)$-BINOL- (or $(S)$-SPINOL- $)^{18,87}$ derived catalysts, the pro- $(S)$ TS meets all criteria and is predicted to be major 
(Figure 8B-I). The pro- $(R)$ TS cannot simply mimic the arrangement of TS $(S)$, since major steric repulsions would occur (Figure 8B-II). This TS is thus disfavored, and will find a new arrangement allowing formation of the $(R)$-product, albeit at some energetic cost. Fulfilling criteria A), B), and D) (Figure 8B-IV) is also disfavored due to the important repulsions between the benzoyl group and the catalyst wall. In the specific case we studied here, the best arrangement for the minor TS involves fulfilling criteria A) B) and C), while positioning the 3-substituent of the azetidine toward the catalyst (Figure 8B-III).

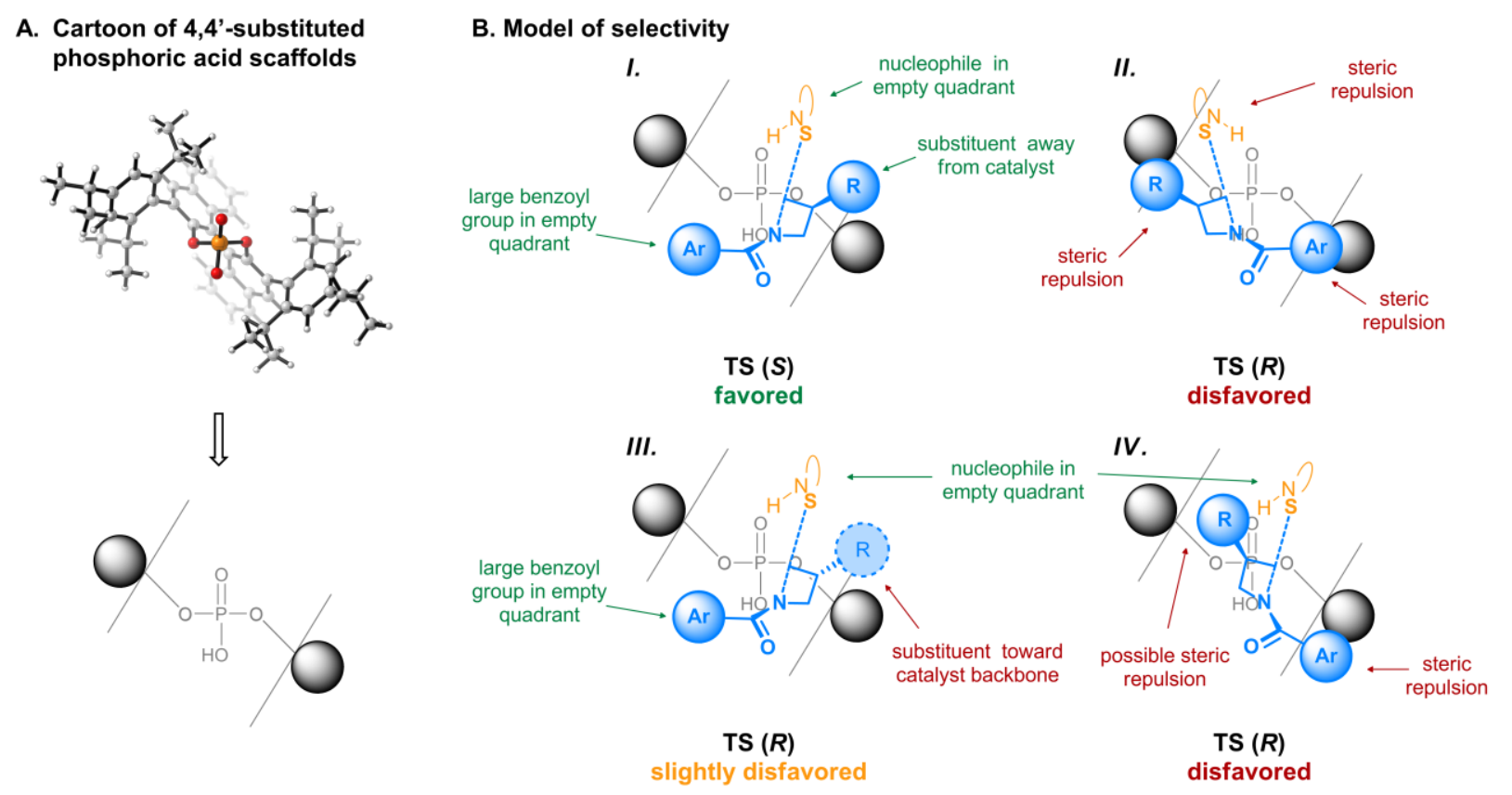

Figure 8: General model of selectivity for $(R)$-BINOL- or $(S)$-SPINOL-derived phosphoric acidcatalyzed azetidine desymmetrizations.

That the ideal arrangement is not possible for TS $(R)$ does not imply that the lowest-energy $(R)$ yielding TS will always involve the exact arrangement as shown in Figure 8B-III. In fact, depending on the nature of the substrates and catalyst, another arrangement could become more stable or new distortions/interactions could impact the energy. To illustrate this point, we have reoptimized TS $9(S)$, TS $9(\boldsymbol{R})$, and all other arrangements optimized with $(\boldsymbol{R})-\mathbf{3 b}$, replacing the three methoxy substituents on the azetidine's benzoyl group with hydrogens. This substrate had been tested by Sun and provided lower selectivity than $1 .{ }^{43}$ Upon re-optimization, the pro- $(R)$ TS derived from arrangement 3 is only $2.2 \mathrm{kcal} \mathrm{mol}^{-1}$ less stable than the one derived from TS $9(\boldsymbol{R})$, itself only $1.5 \mathrm{kcal} \mathrm{mol}^{-1}$ higher than the one derived from TS $9(S)$ (Figure S10 and Table S3). This matches the experimental observation of lower selectivity, but also indicates that alternative arrangements are much closer in energy than with the trimethoxybenzoyl group of $\mathbf{1}$. Thus, although the identity of the lowest-energy structures will depend on each substrate/catalyst combination, the origin of the selectivity remains the same for this reaction: the minor TS cannot 
accommodate all three bulky groups in their preferred positions, due to the chiral nature of the catalyst pocket. Therefore, the above model can predict which enantiomer is favored and provide a rationale for this behavior, but cannot predict which geometry the minor TS will employ. It also cannot predict a magnitude of selectivity. This is in line with other intuitive organic chemistry models for chiral phosphoric acids, ${ }^{33,51,54}$ or famous qualitative examples such as the Felkin$\mathrm{Anh}^{88-90}$ or Corey-Bakshi-Shibata models. ${ }^{91-94}$

\section{Conclusions}

In conclusion, we have studied the chiral phosphoric acid-catalyzed intermolecular desymmetrization of meso-acyl-azetidines reported by Sun, using state-of-the-art DFT calculations. Our results indicate that the reaction is kinetically-controlled and proceeds through bifunctional activation of the azetidine nitrogen and of the thione tautomer of the mercaptobenzothiazole nucleophile. Significant catalyst poisoning explains the low reactivity observed in this system. The calculations accurately reproduce experimental selectivity and the difference in energy between the major pro- $(S)$ and the minor pro- $(R)$ TSs is attributed to a combination of distortions and interactions. We have shown that the true origins of the selectivity cannot be assigned simply by comparing the two stereodetermining TSs to each other since they showcase different arrangements of the substrates relative to the catalyst structure. Instead, a complete analysis of the possible arrangements and conformations was necessary. Our results showed that the transition complexes in this reaction are highly-organized, following strict primary orbital requirements. Using steric maps, we have shown that only the pro- $(S)$ arrangements can fit easily in the chiral pocket of the catalyst. Considering the preferred orientation of the reaction axis in CPA-catalyzed desymmetrizations, the bulky trimethoxybenzoyl group on the azetidine is the main functional group discriminating between potential arrangements of the minor TS, and as such is the main origin of selectivity. Our approach of comparing TSs optimized with a model catalyst to the structures optimized with the full catalyst allowed for the development of a general model for this reaction. We anticipate that this approach will be helpful in the study of other types of enantioselective transformations, and work in that direction in ongoing in our group.

\section{Supporting Information}

Supporting information: full computational details, additional figures and discussion, energies and XYZ coordinates of all computed structures.

\section{Conflicts of interest}

There are no conflicts to declare.

\section{Acknowledgements}


Startup funds from NJIT are gratefully acknowledged. Calculations for this research were performed on the Kong and Lochness clusters at NJIT and on the Extreme Science and Engineering Discovery Environment (XSEDE, allocation number TG-CHE190061), which is supported by the National Science Foundation (grant number ACI-1548562). P.A.C thanks Dr. Floris Buttard (NJIT) and Prof. Shuming Chen (Oberlin College) for their critical comments and suggestions during the preparation of this manuscript.

\section{References}

1. Trost, B. M., Asymmetric catalysis: An enabling science. Proc. Natl. Acad. Sci. U. S. A 2004, 101 (15), 5348-5355.

2. $\quad$ Ojima, I., Catalytic asymmetric synthesis. John Wiley \& Sons: Hoboken, NJ, 2010; Vol.

3.

3. Houk, K.; Paddon-Row, M.; Rondan, N.; Wu, Y.; Brown, F.; Spellmeyer, D.; Metz, J.; Li, Y.; Loncharich, R., Theory and modeling of stereoselective organic reactions. Science 1986, 231 (4742), 1108-1117.

4. Simon, L.; Goodman, J. M., How reliable are DFT transition structures? Comparison of GGA, hybrid-meta-GGA and meta-GGA functionals. Org. Biomol. Chem. 2011, 9 (3), 689-700. 5. Lam, Y.-h.; Grayson, M. N.; Holland, M. C.; Simon, A.; Houk, K. N., Theory and Modeling of Asymmetric Catalytic Reactions. Acc. Chem. Res. 2016, 49 (4), 750-762.

6. Sterling, A. J.; Zavitsanou, S.; Ford, J.; Duarte, F., Selectivity in organocatalysis-From qualitative to quantitative predictive models. WIREs Comput. Mol. Sci. 2021, e1518.

7. Milo, A.; Neel, A. J.; Toste, F. D.; Sigman, M. S., A data-intensive approach to mechanistic elucidation applied to chiral anion catalysis. Science 2015, 347 (6223), 737-743. 8. Neel, A. J.; Milo, A.; Sigman, M. S.; Toste, F. D., Enantiodivergent Fluorination of Allylic Alcohols: Data Set Design Reveals Structural Interplay between Achiral Directing Group and Chiral Anion. J. Am. Chem. Soc. 2016, 138 (11), 3863-3875.

9. Reid, J. P.; Proctor, R. S. J.; Sigman, M. S.; Phipps, R. J., Predictive Multivariate Linear Regression Analysis Guides Successful Catalytic Enantioselective Minisci Reactions of Diazines. J. Am. Chem. Soc. 2019, 141 (48), 19178-19185.

10. Reid, J. P.; Sigman, M. S., Holistic prediction of enantioselectivity in asymmetric catalysis. Nature 2019, 571 (7765), 343-348.

11. Levin, M. D.; Ovian, J. M.; Read, J. A.; Sigman, M. S.; Jacobsen, E. N., Catalytic Enantioselective Synthesis of Difluorinated Alkyl Bromides. J. Am. Chem. Soc. 2020, 142 (35), 14831-14837.

12. Miró, J.; Gensch, T.; Ellwart, M.; Han, S.-J.; Lin, H.-H.; Sigman, M. S.; Toste, F. D., Enantioselective Allenoate-Claisen Rearrangement Using Chiral Phosphate Catalysts. J. Am.

Chem. Soc. 2020, 142 (13), 6390-6399.

13. Robinson, S. G.; Wu, X.; Jiang, B.; Sigman, M. S.; Lin, S., Mechanistic Studies Inform Design of Improved Ti(salen) Catalysts for Enantioselective [3 + 2] Cycloaddition. J. Am. Chem. Soc. 2020, 142 (43), 18471-18482.

14. Tsai, C.-C.; Sandford, C.; Wu, T.; Chen, B.; Sigman, M. S.; Toste, F. D., Enantioselective Intramolecular Allylic Substitution via Synergistic Palladium/Chiral Phosphoric 
Acid Catalysis: Insight into Stereoinduction through Statistical Modeling. Angew. Chem. Int. Ed. 2020, 59 (34), 14647-14655.

15. Werth, J.; Sigman, M. S., Connecting and Analyzing Enantioselective Bifunctional Hydrogen Bond Donor Catalysis Using Data Science Tools. J. Am. Chem. Soc. 2020, 142 (38), 16382-16391.

16. Sigman, M. S.; Harper, K. C.; Bess, E. N.; Milo, A., The Development of Multidimensional Analysis Tools for Asymmetric Catalysis and Beyond. Acc. Chem. Res. 2016, 49 (6), 1292-1301.

17. Houk, K. N.; List, B., Asymmetric Organocatalysis. Acc. Chem. Res. 2004, 37 (8).

18. Parmar, D.; Sugiono, E.; Raja, S.; Rueping, M., Complete Field Guide to Asymmetric BINOL-Phosphate Derived Bronsted Acid and Metal Catalysis: History and Classification by Mode of Activation; Bronsted Acidity, Hydrogen Bonding, Ion Pairing, and Metal Phosphates. Chem. Rev. 2014, 114 (18), 9047-9153.

19. Maji, R.; Mallojjala, S. C.; Wheeler, S. E., Chiral phosphoric acid catalysis: from numbers to insights. Chem. Soc. Rev. 2018, 47 (4), 1142-1158.

20. Simón, L.; Goodman, J. M., DFT Study on the Factors Determining the Enantioselectivity of Friedel-Crafts Reactions of Indole with N-Acyl and N-Tosylimines Catalyzed by BINOL-Phosphoric Acid Derivatives. J. Org. Chem. 2010, 75 (3), 589-597. 21. Hirata, T.; Yamanaka, M., DFT Study of Chiral-Phosphoric-Acid-Catalyzed Enantioselective Friedel-Crafts Reaction of Indole with Nitroalkene: Bifunctionality and Substituent Effect of Phosphoric Acid. Chem. Asian J. 2011, 6 (2), 510-516.

22. Simón, L.; Goodman, J. M., A Model for the Enantioselectivity of Imine Reactions Catalyzed by BINOL-Phosphoric Acid Catalysts. J. Org. Chem. 2011, 76 (6), 1775-1788. 23. Grayson, M. N.; Pellegrinet, S. C.; Goodman, J. M., Mechanistic Insights into the BINOL-Derived Phosphoric Acid-Catalyzed Asymmetric Allylboration of Aldehydes. J. Am. Chem. Soc. 2012, 134 (5), 2716-2722.

24. Grayson, M. N.; Goodman, J. M., Understanding the Mechanism of the Asymmetric Propargylation of Aldehydes Promoted by 1,1'-Bi-2-naphthol-Derived Catalysts. J. Am. Chem. Soc. 2013, 135 (16), 6142-6148.

25. Reid, J. P.; Goodman, J. M., Goldilocks Catalysts: Computational Insights into the Role of the 3,3' Substituents on the Selectivity of BINOL-Derived Phosphoric Acid Catalysts. J. Am. Chem. Soc. 2016, 138 (25), 7910-7917.

26. Simon, L.; Paton, R. S., QM/MM study on the enantioselectivity of spiroacetalization catalysed by an imidodiphosphoric acid catalyst: how confinement works. Org. Biomol. Chem. 2016, 14 (11), 3031-3039.

27. Reid, J. P.; Goodman, J. M., Transfer hydrogenation of ortho-hydroxybenzophenone ketimines catalysed by BINOL-derived phosphoric acid occurs by a 14-membered bifunctional transition structure. Org. Biomol. Chem. 2017, 15 (33), 6943-6947.

28. Zahrt, A. F.; Henle, J. J.; Rose, B. T.; Wang, Y.; Darrow, W. T.; Denmark, S. E., Prediction of higher-selectivity catalysts by computer-driven workflow and machine learning. Science 2019, 363 (6424), eaau5631.

29. Ermanis, K.; Colgan, A. C.; Proctor, R. S. J.; Hadrys, B. W.; Phipps, R. J.; Goodman, J. M., A Computational and Experimental Investigation of the Origin of Selectivity in the Chiral Phosphoric Acid Catalyzed Enantioselective Minisci Reaction. J. Am. Chem. Soc. 2020, 142 (50), 21091-21101. 
30. Laconsay, C. J.; Seguin, T. J.; Wheeler, S. E., Modulating Stereoselectivity through Electrostatic Interactions in a SPINOL-Phosphoric Acid-Catalyzed Synthesis of 2,3-

Dihydroquinazolinones. ACS Catal. 2020, 10 (20), 12292-12299.

31. Maskeri, M. A.; Brueckner, A. C.; Feoktistova, T.; O'Connor, M. J.; Walden, D. M.; Cheong, P. H.-Y.; Scheidt, K. A., Mechanism and origins of selectivity in the enantioselective oxa-Pictet-Spengler reaction: a cooperative catalytic complex from a hydrogen bond donor and chiral phosphoric acid. Chem. Sci. 2020, 11 (33), 8736-8743.

32. Falcone, B. N.; Grayson, M. N., Understanding the mechanism of the chiral phosphoric acid-catalyzed aza-Cope rearrangement. Org. Biomol. Chem. 2021.

33. Reid, J. P.; Simón, L.; Goodman, J. M., A Practical Guide for Predicting the Stereochemistry of Bifunctional Phosphoric Acid Catalyzed Reactions of Imines. Acc. Chem. Res. 2016, 49 (5), 1029-1041.

34. Rowland, E. B.; Rowland, G. B.; Rivera-Otero, E.; Antilla, J. C., Bronsted acidcatalyzed desymmetrization of meso-aziridines. J. Am. Chem. Soc. 2007, 129 (40), 12084-12085. 35. Larson, S. E.; Baso, J. C.; Li, G.; Antilla, J. C., Chiral Phosphoric Acid-Catalyzed Desymmetrization of meso-Aziridines with Functionalized Mercaptans. Org. Lett. 2009, 11 (22), 5186-5189.

36. Sala, G. D.; Lattanzi, A., Highly Enantioselective Synthesis of $\beta$-Amidophenylthioethers by Organocatalytic Desymmetrization of meso-Aziridines. Org. Lett. 2009, 11 (15), 3330-3333. 37. Senatore, M.; Lattanzi, A.; Santoro, S.; Santi, C.; Sala, G. D., A general phosphoric acid-catalyzed desymmetrization of meso-aziridines with silylated selenium nucleophiles. Org. Biomol. Chem. 2011, 9 (18), 6205-6207.

38. Monaco, M. R.; Poladura, B.; Diaz de Los Bernardos, M.; Leutzsch, M.; Goddard, R.; List, B., Activation of Carboxylic Acids in Asymmetric Organocatalysis. Angew. Chem. Int. Ed. 2014, 53 (27), 7063-7067.

39. Sun, S.; Wang, Z.; Li, S.; Zhou, C.; Song, L.; Huang, H.; Sun, J., An Organocatalytic Kinetic Resolution of Aziridines by Thiol Nucleophiles. Org. Lett. 2021, 23 (2), 554-558. 40. Wang, Z.; Law, W. K.; Sun, J., Chiral Phosphoric Acid Catalyzed Enantioselective Desymmetrization of meso-Epoxides by Thiols. Org. Lett. 2013, 15 (23), 5964-5966.

41. Monaco, M. R.; Prévost, S.; List, B., Catalytic Asymmetric Synthesis of Thiols. J. Am. Chem. Soc. 2014, 136 (49), 16982-16985.

42. Liao, S.; Leutzsch, M.; Monaco, M. R.; List, B., Catalytic Enantioselective Conversion of Epoxides to Thiiranes. J. Am. Chem. Soc. 2016, 138 (16), 5230-5233.

43. Wang, Z.; Sheong, F. K.; Sung, H. H. Y.; Williams, I. D.; Lin, Z.; Sun, J., Catalytic Enantioselective Intermolecular Desymmetrization of Azetidines. J. Am. Chem. Soc. 2015, 137 (18), 5895-5898.

44. Chen, Z.; Wang, Z.; Sun, J., Catalytic Enantioselective Synthesis of Tetrahydroisoquinolines and Their Analogues Bearing a C4 Stereocenter: Formal Synthesis of (+)-(8S,13R)-Cyclocelabenzine. Chem. Eur. J. 2013, 19 (26), 8426-8430.

45. Wang, Z.; Chen, Z.; Sun, J., Catalytic Enantioselective Intermolecular Desymmetrization of 3-Substituted Oxetanes. Angew. Chem. Int. Ed. 2013, 52 (26), 6685-6688.

46. Yang, W.; Sun, J., Organocatalytic Enantioselective Synthesis of 1,4-Dioxanes and Other Oxa-Heterocycles by Oxetane Desymmetrization. Angew. Chem. Int. Ed. 2016, 55 (5), 18681871. 
47. Yang, W.; Wang, Z.; Sun, J., Enantioselective Oxetane Ring Opening with Chloride: Unusual Use of Wet Molecular Sieves for the Controlled Release of HCl. Angew. Chem. Int. Ed. 2016, 55 (24), 6954-6958.

48. Zhang, R.; Guo, W.; Duan, M.; Houk, K. N.; Sun, J., Asymmetric Desymmetrization of Oxetanes for the Synthesis of Chiral Tetrahydrothiophenes and Tetrahydroselenophenes. Angew. Chem. Int. Ed. 2019, 58 (50), 18055-18060.

49. Zou, X.; Sun, G.; Huang, H.; Wang, J.; Yang, W.; Sun, J., Catalytic Enantioselective Synthesis of 1,4-Benzodioxepines. Org. Lett. 2020, 22 (1), 249-252.

50. Ajitha, M. J.; Huang, K.-W., Role of keto-enol tautomerization in a chiral phosphoric acid catalyzed asymmetric thiocarboxylysis of meso-epoxide: a DFT study. Org. Biomol. Chem. 2015, 13 (45), 10981-10985.

51. Champagne, P. A.; Houk, K. N., Origins of Selectivity and General Model for Chiral Phosphoric Acid-Catalyzed Oxetane Desymmetrizations. J. Am. Chem. Soc. 2016, 138 (38), 12356-12359.

52. Seguin, T. J.; Wheeler, S. E., Electrostatic Basis for Enantioselective Brønsted-AcidCatalyzed Asymmetric Ring Openings of meso-Epoxides. ACS Catal. 2016, 6 (4), 2681-2688.

53. Seguin, T. J.; Wheeler, S. E., Competing Noncovalent Interactions Control the Stereoselectivity of Chiral Phosphoric Acid Catalyzed Ring Openings of 3-Substituted Oxetanes. ACS Catal. 2016, 6 (10), 7222-7228.

54. Maji, R.; Champagne, P. A.; Houk, K. N.; Wheeler, S. E., Activation Mode and Origin of Selectivity in Chiral Phosphoric Acid-Catalyzed Oxacycle Formation by Intramolecular Oxetane Desymmetrizations. ACS Catal. 2017, 7 (10), 7332-7339.

55. Borissov, A.; Davies, T. Q.; Ellis, S. R.; Fleming, T. A.; Richardson, M. S. W.; Dixon, D. J., Organocatalytic enantioselective desymmetrisation. Chem. Soc. Rev. 2016, 45 (20), 54745540 .

56. Mughal, H.; Szostak, M., Recent advances in the synthesis and reactivity of azetidines: strain-driven character of the four-membered heterocycle. Org. Biomol. Chem. 2021, 19 (15), 3274-3286.

57. Grimme, S.; Ehrlich, S.; Goerigk, L., Effect of the damping function in dispersion corrected density functional theory. J. Comput. Chem. 2011, 32 (7), 1456-1465.

58. Barone, V.; Cossi, M., Quantum Calculation of Molecular Energies and Energy Gradients in Solution by a Conductor Solvent Model. J. Phys. Chem. A 1998, 102 (11), 1995-2001.

59. Cossi, M.; Rega, N.; Scalmani, G.; Barone, V., Energies, structures, and electronic properties of molecules in solution with the C-PCM solvation model. J. Comput. Chem. 2003, 24 (6), 669-681.

60. Li, F.; Korenaga, T.; Nakanishi, T.; Kikuchi, J.; Terada, M., Chiral Phosphoric Acid Catalyzed Enantioselective Ring Expansion Reaction of 1,3-Dithiane Derivatives: Case Study of the Nature of Ion-Pairing Interaction. J. Am. Chem. Soc. 2018, 140 (7), 2629-2642.

61. Zhu, L.; Yuan, H.; Zhang, J., The effect of CF3 functional group substituent on bifunctional activation model and enantioselectivity for BINOL N-triflylphosphoramides catalyzed rearrangement reaction. J. Catal. 2020, 383, 230-238.

62. Wang, S.; Arguelles, A. J.; Tay, J.-H.; Hotta, M.; Zimmerman, P. M.; Nagorny, P., Experimental and Computational Studies on Regiodivergent Chiral Phosphoric Acid Catalyzed Cycloisomerization of Mupirocin Methyl Ester. Chem. Eur. J. 2020, 26 (20), 4583-4591.

63. Grimme, S.; Bannwarth, C.; Dohm, S.; Hansen, A.; Pisarek, J.; Pracht, P.; Seibert, J.; Neese, F., Fully Automated Quantum-Chemistry-Based Computation of Spin-Spin-Coupled 
Nuclear Magnetic Resonance Spectra. Angewandte Chemie International Edition 2017, 56 (46), 14763-14769.

64. Grimme, S., Exploration of Chemical Compound, Conformer, and Reaction Space with Meta-Dynamics Simulations Based on Tight-Binding Quantum Chemical Calculations. Journal of Chemical Theory and Computation 2019, 15 (5), 2847-2862.

65. Marenich, A. V.; Cramer, C. J.; Truhlar, D. G., Universal Solvation Model Based on Solute Electron Density and on a Continuum Model of the Solvent Defined by the Bulk Dielectric Constant and Atomic Surface Tensions. J. Phys. Chem. B 2009, 113 (18), 6378-6396.

66. Legault, C. Y. CYLview, 1.0b; Université de Sherbrooke, 2009

(http://www.cylview.org).

67. Lai, J.; Fianchini, M.; Pericàs, M. A., Development of Immobilized SPINOL-Derived Chiral Phosphoric Acids for Catalytic Continuous Flow Processes. Use in the Catalytic Desymmetrization of 3,3-Disubstituted Oxetanes. ACS Catal. 2020, 10 (24), 14971-14983. 68. Kozuch, S.; Shaik, S., How to Conceptualize Catalytic Cycles? The Energetic Span Model. Accounts of Chemical Research 2011, 44 (2), 101-110.

69. Gridnev, I. D.; Kouchi, M.; Sorimachi, K.; Terada, M., On the mechanism of stereoselection in direct Mannich reaction catalyzed by BINOL-derived phosphoric acids. Tetrahedron Lett. 2007, 48 (3), 497-500.

70. Marcelli, T.; Hammar, P.; Himo, F., Phosphoric Acid Catalyzed Enantioselective Transfer Hydrogenation of Imines: A Density Functional Theory Study of Reaction Mechanism and the Origins of Enantioselectivity. Chem. Eur. J. 2008, 14 (28), 8562-8571.

71. Bickelhaupt, F. M.; Houk, K. N., Analyzing Reaction Rates with the Distortion/Interaction-Activation Strain Model. Angew. Chem. Int. Ed. 2017, 56 (34), 1007010086.

72. Johnson, E. R.; Keinan, S.; Mori-Sánchez, P.; Contreras-García, J.; Cohen, A. J.; Yang, W., Revealing Noncovalent Interactions. J. Am. Chem. Soc. 2010, 132 (18), 6498-6506.

73. Lu, T.; Chen, F., Multiwfn: A multifunctional wavefunction analyzer. J. Comput. Chem. 2012, 33 (5), 580-592.

74. Poater, A.; Cosenza, B.; Correa, A.; Giudice, S.; Ragone, F.; Scarano, V.; Cavallo, L., SambVca: A Web Application for the Calculation of the Buried Volume of N-Heterocyclic Carbene Ligands. Eur. J. Inorg. Chem. 2009, 2009 (13), 1759-1766.

75. Poater, A.; Ragone, F.; Mariz, R.; Dorta, R.; Cavallo, L., Comparing the Enantioselective Power of Steric and Electrostatic Effects in Transition-Metal-Catalyzed Asymmetric Synthesis. Chem. Eur. J. 2010, 16 (48), 14348-14353.

76. Ragone, F.; Poater, A.; Cavallo, L., Flexibility of N-Heterocyclic Carbene Ligands in Ruthenium Complexes Relevant to Olefin Metathesis and Their Impact in the First Coordination Sphere of the Metal. J. Am. Chem. Soc. 2010, 132 (12), 4249-4258.

77. Wucher, P.; Caporaso, L.; Roesle, P.; Ragone, F.; Cavallo, L.; Mecking, S.; GöttkerSchnetmann, I., Breaking the regioselectivity rule for acrylate insertion in the Mizoroki-Heck reaction. Proc. Natl. Acad. Sci. U. S. A. 2011, 108 (22), 8955-8959.

78. Poater, A.; Falivene, L.; Urbina-Blanco, C. A.; Manzini, S.; Nolan, S. P.; Cavallo, L., Steric Maps to Evaluate the Role of Steric Hindrance on the IPr NHC Ligand. Procedia Comput. Sci. 2013, 18, 845-854.

79. Falivene, L.; Cao, Z.; Petta, A.; Serra, L.; Poater, A.; Oliva, R.; Scarano, V.; Cavallo, L., Towards the online computer-aided design of catalytic pockets. Nature Chem. 2019, 11 (10), 872-879. 
80. Liu, P.; Montgomery, J.; Houk, K. N., Ligand Steric Contours To Understand the Effects of N-Heterocyclic Carbene Ligands on the Reversal of Regioselectivity in Ni-Catalyzed Reductive Couplings of Alkynes and Aldehydes. J. Am. Chem. Soc. 2011, 133 (18), 6956-6959. 81. Hong, X.; Liu, P.; Houk, K. N., Mechanism and Origins of Ligand-Controlled Selectivities in $[\mathrm{Ni}(\mathrm{NHC})]$-Catalyzed Intramolecular $(5+2)$ Cycloadditions and Homo-Ene Reactions: A Theoretical Study. J. Am. Chem. Soc. 2013, 135 (4), 1456-1462.

82. Lu, G.; Fang, C.; Xu, T.; Dong, G.; Liu, P., Computational Study of Rh-Catalyzed Carboacylation of Olefins: Ligand-Promoted Rhodacycle Isomerization Enables Regioselective C-C Bond Functionalization of Benzocyclobutenones. J. Am. Chem. Soc. 2015, 137 (25), $8274-$ 8283.

83. Huang, G.; Liu, P., Mechanism and Origins of Ligand-Controlled Linear Versus Branched Selectivity of Iridium-Catalyzed Hydroarylation of Alkenes. ACS Catal. 2016, 6 (2), 809-820.

84. Gomez-Suarez, A.; Nelson, D. J.; Nolan, S. P., Quantifying and understanding the steric properties of N-heterocyclic carbenes. Chem. Commun. 2017, 53 (18), 2650-2660.

85. https://www.molnac.unisa.it/OMtools/sambvca2.1/index.html

86. Krenske, E. H.; Houk, K. N., Aromatic Interactions as Control Elements in Stereoselective Organic Reactions. Acc. Chem. Res. 2013, 46 (4), 979-989.

87. (R)-BINOL and (S)-SPINOL catalysts have the same pocket chirality, hence why the model is applicable to both.

88. Nguyen Trong Anh, O. E., THEORETICAL INTERPRETATION OF 1-2 ASYMMETRIC INDUCTION. THE IMPORTANCE OF ANTIPERIPLANARITY. Nouv. $J$. Chim. 1977, 1 (1), 61-70.

89. Wu, Y. D.; Houk, K. N., Electronic and conformational effects on .pi.-facial stereoselectivity in nucleophilic additions to carbonyl compounds. J. Am. Chem. Soc. 1987, 109 (3), 908-910.

90. Smith, Richard J.; Trzoss, M.; Bühl, M.; Bienz, S., The Cram Rule Revisited Once More - Revision of the Felkin-Anh Model. Eur. J. Org. Chem. 2002, 2002 (16), 2770-2775. 91. Corey, E. J.; Bakshi, R. K.; Shibata, S., Highly enantioselective borane reduction of ketones catalyzed by chiral oxazaborolidines. Mechanism and synthetic implications. J. Am. Chem. Soc. 1987, 109 (18), 5551-5553.

92. Nevalainen, V., Quantum chemical modeling of chiral catalysis. Part 15. On the role of hydride-bridged borane - alkoxyborane complexes in the catalytic enantioselective reduction of ketones promoted by chiral oxazaborolidines. Tetrahedron: Asymmetry 1994, 5 (2), 289-296. 93. Quallich, G. J.; Blake, J. F.; Woodall, T. M., A combined synthetic and ab initio study of chiral oxazaborolidines structure and enantioselectivity relationships. J. Am. Chem. Soc. 1994, 116 (19), 8516-8525.

94. Alagona, G.; Ghio, C.; Persico, M.; Tomasi, S., Quantum Mechanical Study of Stereoselectivity in the Oxazaborolidine-Catalyzed Reduction of Acetophenone. J. Am. Chem. Soc. 2003, 125 (33), 10027-10039. 


\section{Table of Contents Entry}<smiles></smiles>

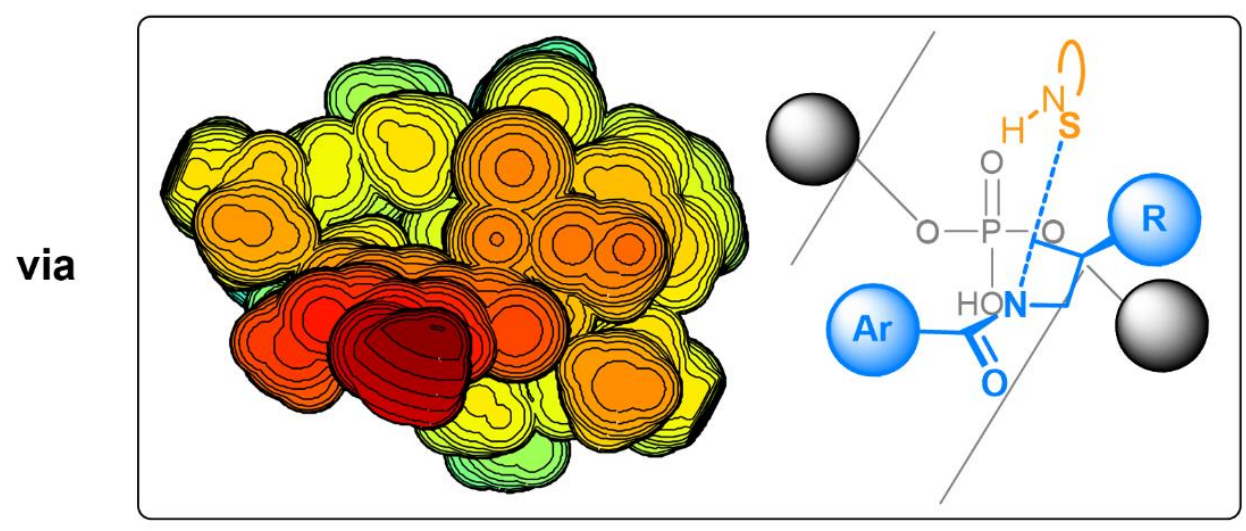

The mechanism and origins of the selectivity in azetidine desymmetrizations have been identified determined using DFT calculations, resulting in the development of a general model of selectivity. A comparison of structures computed with model and full catalysts pinpoints the benzoyl protecting group of the azetidine as the main driver of selectivity, a result that could not be obtained only through distortion/interaction analysis of the stereodetermining transition structures. 